\title{
Influence of different durations of estrogen deficiency on alveolar bone loss in rats
}

\section{Susana Ungaro Amadei(a) Daniela Martins de Souza ${ }^{(a)}$ Adriana Aigotti Haberbeck Brandão(b)}

Rosilene Fernandes da Rocha ${ }^{(b)}$

(a) Department of Dentistry, School of Dentistry of Pindamonhangaba, FAPI - Faculty of Pindamonhangaba, Pindamonhangaba, SP, Brazil.

(b) Department of Bioscience and Oral Diagnosis, School of Dentistry of São José dos Campos, UNESP - Univ. Estadual Paulista, São José dos Campos, SP, Brazil.
Declaration of Interests: The authors certify that they have no commercial or associative interest that represents a conflict of interest in connection with the manuscript.

\section{Corresponding author:}

Susana Ungaro Amadei

E-mail: suamadei@yahoo.com.br

Received for publication on Aug 01, 2011 Accepted for publication on Oct 14, 2011

\begin{abstract}
The purpose of this study was to morphometrically evaluate the influence of different durations of ovariectomy-induced estrogen deficiency on alveolar bone loss associated with ligature-induced bone loss in rats. Sixty female Wistar rats were randomly assigned to ovariectomy (OVX test group) or sham operation (SHAM control group). The OVX and SHAM groups were each distributed into three subgroups of ten rats each according to the duration of estrogen deficiency (30, 60 and 90 postoperative days). In all groups, for the last 30 days of the experimental period, cotton ligatures were placed around the cervix of the right upper second molar; the contralateral tooth was left unligated to serve as a control. The maxillary bones were removed, and the alveolar bone loss was analyzed by measuring the distance between the cementoenamel junction and the alveolar bone crest at the buccal site of the right upper second molar. A comparison between the ligated and unligated groups verified the presence of ligature-induced alveolar bone loss $(p<0.05)$. No significant differences were observed among the unligated groups $(p>0.05)$. A significant increase in bone loss was observed when ligation occurred 90 days after ovariectomy compared with the sham group $(\mathrm{p}<0.05)$. These results demonstrate that long-term estrogen deficiency affects ligatureinduced alveolar bone loss.
\end{abstract}

Descriptors: Alveolar Bone Loss; Periodontitis; Bone Diseases.

\section{Introduction}

Periodontal disease is an inflammatory disease of the periodontal tissues that is initiated by bacteria in dental plaque and results in the loss of tooth-supporting tissues, including the alveolar bone. Although the presence of periodontal pathogens is necessary for the initiation of inflammation, the progression of periodontal disease depends equally on the host response to various pathogenic bacterial products and components. ${ }^{1,2}$

Most elderly people perceive their oral health as important to their quality of life for various physical, social and psychological reasons. ${ }^{3} \mathrm{Be}-$ cause of the increased life expectancy in many countries, elderly individuals now have more opportunities for dental treatment. ${ }^{4}$ Some studies suggest a positive relationship between systemic osteoporosis and oral bone loss $^{5,6}$ and between osteoporosis and tooth loss. ${ }^{7,8}$

Ovariectomized rats have been used as an animal model to simulate human postmenopausal accelerated bone loss. ${ }^{9,10}$ Previous studies have 
used morphometric analysis to evaluate alveolar bone loss in ligature-induced periodontitis in rats. ${ }^{11-}$ ${ }^{14}$ However, the mechanism underlying the bone loss remains unclear. The deficiency of sex steroids, particularly estrogen, is considered to be the main cause of osteoporosis, although there are many other factors involved..$^{15}$

Few studies exist that evaluate the relationship between estrogen deficiency and periodontal disease associated with bone loss in rats. ${ }^{9,10}$ Thus, the aim of this study was to morphometrically evaluate the influence of different durations of estrogen deficiency on the ligature-induced alveolar bone loss.

\section{Methodology Animals}

Sixty 90-day-old adult female Wistar rats were randomly assigned to 2 groups: one group was ovariectomized (OVX: test group), and the other was submitted to sham operation (SHAM: control group).

All the rats were housed under similar conditions and received standard rat chow (Guabi Nutrilador, Mogiana Alimentos, Campinas, Brazil) and water ad libitum. The Institutional Animal Research Committee at the University of São José dos Campos (São Paulo, Brazil) approved the protocol.

\section{Experimental procedures}

The rats were weighed and anesthetized intramuscularly with a combination of $2 \%$ xylazine (Rompun; Bayer, São Paulo, Brazil; 13 mg/kg body weight) and ketamine (Francotar; Virbac, Roseira, Brazil, $33 \mathrm{mg} / \mathrm{kg}$ body weight). Bilateral ovariectomies were performed in rats of the OVX group. The remaining rats were submitted to sham surgeries in which the ovaries were lifted and then returned intact to their original position.

The OVX and SHAM groups consisted of thirty rats each and were randomly distributed into three subgroups of ten rats according to the duration of the period after surgery. The durations were 30, 60 and 90 days after the operation.

In all groups, 30 days before the end of the experimental period, the same general anesthesia was administrated intramuscularly, followed by induc- tion of alveolar bone loss by placement of cotton ligatures around the cervix of the right upper second molar. The contralateral teeth were left unligated to serve as controls. The ligature was knotted on the buccal side of the tooth. In group OVX (30 days), the cotton ligature was placed immediately after ovariectomy.

At the end of the experimental period of each subgroup, the rats were weighed and euthanized, the ligatures were removed and the maxillary bones were fixed in $10 \%$ neutral formalin for $48 \mathrm{~h}$.

\section{Morphometric analysis}

The right maxilla of each rat was defleshed and stained with aqueous methylene blue solution $(1 \%)$ to differentiate the bone from the teeth.

Alveolar bone loss was evaluated morphometrically by measuring the distance between the cementoenamel junction (CEJ) and the alveolar bone crest $(\mathrm{ABC})$ at 2 buccal sites for each maxilla (Figures 1 and 2). Three measurements at each site were obtained along the long axis of the roots of the upper second molar (25× magnification) using the Image Tool v.3.0 image analysis system (UTHSCSA, San Antonio, TX, USA). The mean of these measurements was used as the measurement of alveolar bone loss in each tooth. For all measurements, the investigators were blinded to the treatment group of the sample.

To obtain sufficient reproducibility of the molar alignment in the images, the teeth did not overlap each other interproximally, and the buccal cusp tip of each molar was superimposed on the corresponding lingual cusp tip.

\section{Statistical Analysis}

The body weights of the rats on postoperative days 30, 60 and 90 were expressed as changes in weight $(\%)$ and submitted to statistical analysis. The independent-samples $t$ test $(\mathrm{p}<0.05)$ was used to compare weight changes between the OVX and SHAM groups for different durations of estrogen deficiency or sufficiency. Intergroup analyses (ANOVA and the Tukey post-hoc test, $\mathrm{p}<0.05$ ) were used separately for the test or control groups to identify significant differences in weight changes among the 


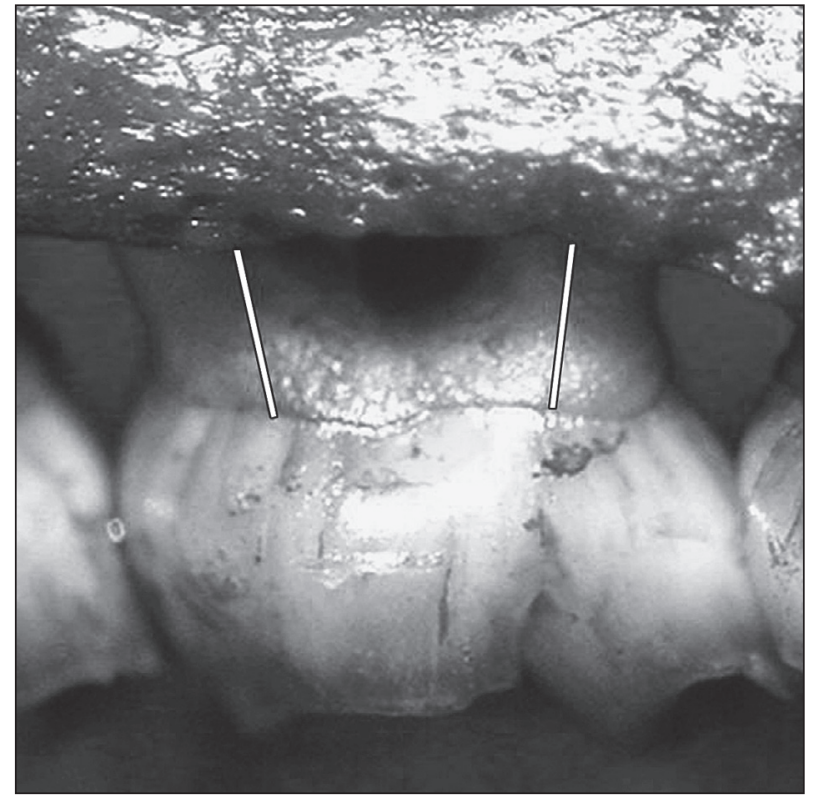

Figure 1 - Photograph of alveolar bone loss morphometrically evaluated by measuring the distance between the cementoenamel junction (CEJ) and alveolar bone crest (ABC) at 2 buccal sites in the ligated maxilla. The lines indicate the distances that were measured for the buccal side.

different durations of estrogen deficiency or sufficiency.

For the morphometric analysis, the data were expressed as the mean and standard deviation $(\mathrm{mm})$, and the independent-samples $t$ test was used for comparisons between the OVX and SHAM groups for the different durations. Intergroup analyses (ANOVA and the Tukey post-hoc test, $\mathrm{p}<0.05$ ) were used separately on the test or control groups to determine significant differences in alveolar bone loss among the different durations of estrogen deficiency or sufficiency.

In addition, the paired $t$ test $(\mathrm{p}<0.05)$ was used to compare the alveolar bone loss between the ligated and unligated teeth in the same rat.

\section{Results \\ Weight analysis}

The rats showed significant differences $(\mathrm{p}<0.05)$ between the mean baseline and mean final weight, with weight gains occurring in all of the experimental groups.

The weight gain in the groups with estrogen deficiency gradually increased $(\mathrm{p}<0.05)$ over time.

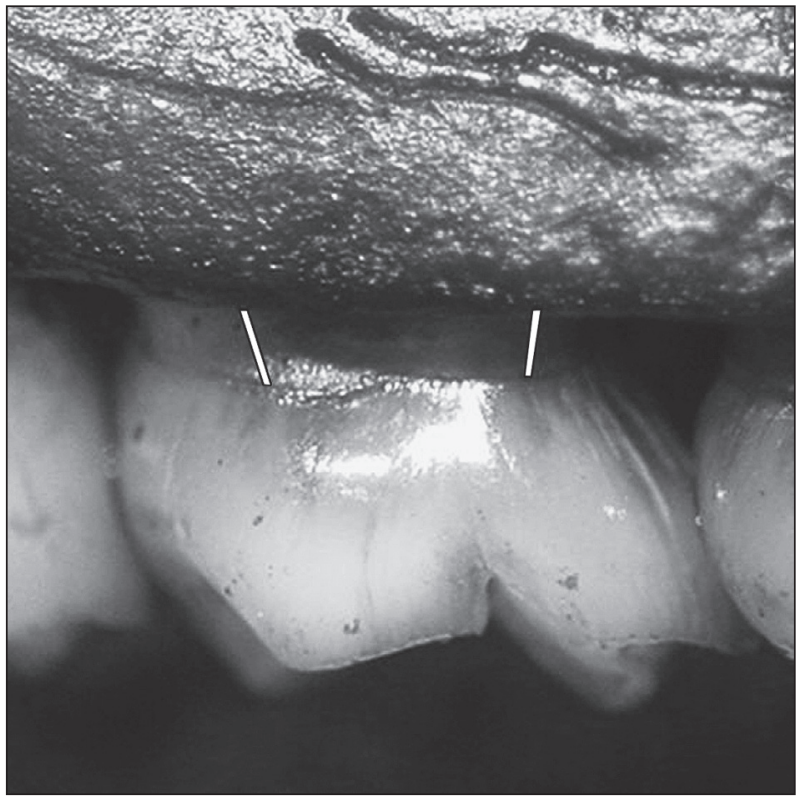

Figure 2 - Photograph of alveolar bone loss morphometrically evaluated by measuring the distance between the cementoenamel junction (CEJ) and the alveolar bone crest $(A B C)$ at 2 buccal sites in the unligated maxilla. The lines indicate the distances that were measured for the buccal side.

Table 1 - Mean ( \pm standard deviation) of the percent weight alteration (\%) for the OVX and SHAM groups ( $\mathrm{n}=10$ rats) group) for different durations of estrogen deficiency and sufficiency.

\begin{tabular}{c|c|c}
\hline $\begin{array}{c}\text { Periods of estrogen } \\
\text { deficiency or sufficiency }\end{array}$ & $\begin{array}{c}\text { OVX } \\
\text { (test) }\end{array}$ & $\begin{array}{c}\text { SHAM } \\
\text { (control) }\end{array}$ \\
\hline 30 days & $20.54 \pm 2.89^{\mathrm{A}}$ & $04.76 \pm 1.55^{\text {a* }}$ \\
\hline 60 days & $25.95 \pm 1.74^{\mathrm{B}}$ & $10.72 \pm 3.04^{\mathrm{a*}}$ \\
\hline 90 days & $29.05 \pm 2.54^{\mathrm{C}}$ & $21.14 \pm 13.10^{\mathrm{b}}$ \\
\hline
\end{tabular}

Capital letters are for OVX; lower-case letters are for SHAM groups. Means followed by different letters differ statistically (intergroup analysis: ANOVA, $p<0.05$, and Tukey test, $p<0.05)$. ${ }^{*}$ Statistically significant differences among groups along the lines (independent-sample $t$ test; $p<0.05$ ).

In the estrogen-sufficient groups, the 90-day group gained significantly more weight than the other groups. There was no significant difference between the 90-day SHAM and OVX groups ( $\mathrm{p}>0.05)$ with regard to weight gain (Table 1).

\section{Morphometric analysis}

Morphometric analysis showed that cotton ligatures placed around the teeth induced alveolar bone loss $(\mathrm{p}<0.05)$ compared with unligated teeth.

For unligated teeth, the intergroup analysis 
showed no significant differences in alveolar bone loss $(p>0.05)$ between the test and control groups. The intergroup analysis showed no significant differences in alveolar bone loss ( $p>0.05)$ among the different durations of estrogen deficiency and sufficiency (Table 2).

When alveolar bone loss was induced, the alveolar bone loss in the rats receiving the ovariectomy $(1.47 \pm 0.08 \mathrm{~mm})$ was significantly greater than that in SHAM rats $(1.41 \pm 0.03 \mathrm{~mm})$ when the ligation was performed 90 days after the surgical procedure. For the ligated teeth, the intergroup analysis showed no significant differences in alveolar bone loss values $(p>0.05)$ among the different durations of estrogen deficiency and sufficiency (Table 3 ).

\section{Discussion}

The purpose of the study was to determine the influence of different durations of estrogen deficiency on the progression of experimental periodontitis in rats. The present study showed that estrogen deficiency does not affect the alveolar bone amount, regardless of plaque accumulation, but results in greater ligature-induced bone loss in rats submitted to 90 days of estrogen deficiency.

Animal models have been used to investigate the influence of estrogen deficiency on the progres- sion of periodontitis ${ }^{9,10}$ because the structure of the periodontal tissue in rats is very similar to that of humans. ${ }^{16}$ Therefore, ovariectomy-induced osteopenia in the rat produces skeletal responses similar to those in post-menopausal women. ${ }^{17}$

A morphometric analysis of defleshed jaws ${ }^{11-}$ $13,18,19$ was applied to assess the amount of periodontal bone in the rats. This analysis is reproducible and can discriminate among experimental groups. ${ }^{20}$ Morphometric and histologic procedures were compared for alveolar bone measurement, and no significant differences were found between the two methods when the amount of bone was measured after ligature placement in rats. ${ }^{21}$

A recent study ${ }^{22}$ morphometrically evaluated bone loss by comparing different locations in experimental periodontitis in rats. The maxilla showed greater bone loss than the mandible, and the bone loss was greater on the buccal side.

Controversies exist in studies involving oral osteoporosis and bone loss in humans. According to Beck, alveolar bone loss is a result of periodontal disease, and osteoporosis is suspected to be linked to this disease. However, Beck reported that it is difficult to establish this relationship because some studies show inappropriate methodology, i.e., small samples and lack of controlling for important fac-
Table 2 - Mean ( \pm standard deviation) of alveolar bone loss $(\mathrm{mm})$ for the OVX and SHAM groups ( $\mathrm{n}=10$ rats/group) without

ligation for different durations of estrogen deficiency and sufficiency.

\begin{tabular}{c|c|c|c}
\hline $\begin{array}{c}\text { Periods of estrogen } \\
\text { deficiency or sufficiency }\end{array}$ & OVX & SHAM & $\begin{array}{c}\text { p value } \\
\text { (independent-sample } t \text { test) }\end{array}$ \\
\hline 30 days (without ligature) & $0.42 \pm 0.03^{\mathrm{A}}$ & $0.41 \pm 0.06^{\mathrm{a}}$ & 0.3878 \\
\hline 60 days (without ligature) & $0.42 \pm 0.03^{\mathrm{A}}$ & $0.42 \pm 0.05^{\mathrm{a}}$ & 0.4789 \\
\hline 90 days (without ligature) & $0.41 \pm 0.04^{\mathrm{A}}$ & $0.40 \pm 0.02^{\mathrm{a}}$ & 0.4756 \\
\hline
\end{tabular}

Capital letters are for OVX; lower case letters are for SHAM groups. Means followed by different letters differ statistically (intergroup analysis: ANOVA, $p<0.05$, and Tukey test, $p<0.05$ ). * Statistically significant differences among groups along the lines (independent sample $t$ test; $p<0.05$ ).
Table 3 - Mean ( \pm standard deviation) alveolar bone loss $(\mathrm{mm})$ for OVX and SHAM groups (10 rats/group) with ligatures applied after different durations of estrogen deficiency and sufficiency.

\begin{tabular}{c|c|c|c}
\hline $\begin{array}{c}\text { Duration of estrogen } \\
\text { deficiency or sufficiency }\end{array}$ & OVX (test) & SHAM (control) & $\begin{array}{c}\text { p value } \\
\text { (independent } t \text { test) }\end{array}$ \\
\hline 30 days (with ligature) & $1.42 \pm 0.05^{\mathrm{A}}$ & $1.40 \pm 0.15^{\mathrm{a}}$ & 0.3601 \\
\hline 60 days (with ligature) & $1.42 \pm 0.08^{\mathrm{A}}$ & $1.39 \pm 0.10^{\mathrm{a}}$ & 0.2771 \\
\hline 90 days (with ligature) & $1.47 \pm 0.08^{\mathrm{A}}$ & $1.41 \pm 0.03^{\mathrm{a}}$ & $0.0183^{*}$ \\
\hline
\end{tabular}

Capital letters are for OVX; lower case letters are for SHAM groups. Means followed by different letters differ statistically (intergroup analysis: ANOVA, $p<0.05$, and Tukey test, $p<0.05$ ). ${ }^{*}$ Statistically significant differences among groups along the lines (independent sample $t$ test; $p<0.05$ ). 
tors common to periodontal disease and osteoporosis, such as age, the habit of smoking, diabetes and certain medications. ${ }^{23}$

The contribution of osteoporosis to tooth loss is difficult to demonstrate because teeth can be lost for several reasons other than the loss of bone support. Among the reasons commonly cited are dental caries, the quality of dental treatment and factors caused by different cultural understanding and varying economic levels. ${ }^{24}$

A possible relationship between estrogen deficiency and alveolar bone loss without the induction of experimental of periodontitis was not verified in this study. Similarly, some studies on animals have observed that osteoporosis itself may not be capable of causing alveolar bone loss; $9,10,25$ in contrast, other studies have shown that estrogen deficiency may have a direct effect on alveolar bone loss in the furcation region. ${ }^{9}$

In the present study, estrogen deficiency for 90 days resulted in greater ligature-induced bone loss in rats. In a previous study, ${ }^{9}$ estrogen deficiency in rats for 81 days resulted in significant alveolar bone loss in experimental periodontitis when the rats were compared with estrogen-sufficient rats; the findings were determined histological in the furca region of the first mandibular molar. In another study, ${ }^{10}$ the rats were evaluated 65 days after ovariectomy, and no morphometric alterations related to estrogen deficiency were observed in the upper maxilla on the buccal face.

\section{References}

1. Listgarten MA. Nature of periodontal disease: Pathogenic mechanisms. J Periodontol Res. 1987 May;22(3):172-8.

2. Genco RJ. Host responses in periodontal diseases: current concepts. J Periodontol. 1992 Apr;63(4 Suppl):338-55.

3. McGrath C, Bedi R. The importance of oral health to older people's quality of life. Gerontology. 1999 Jul;16(1):59-63.

4. Howson CP. Perspectives and needs for health in the $21^{\text {st }}$ century: $20^{\text {th }}$-century paradigms in $21^{\text {st }}$-century science. $\mathrm{J}$ Hum Virol. 2000 Mar-Apr;3(2):94-103.

5. Southard KA, Southard TE, Schlechte JA, Meis PA. The relashionship between the density of the alveolar process and that of post-cranial bone. J Dent Res. 2000 Apr;79(4):964-9.
In sheep, Johnson et al. ${ }^{26}$ observed significant inflammatory periodontal alterations 90 days after ovariectomy compared with controls.

Increased bone loss was only observed when the ligature was applied after 90 days of estrogen deficiency. It is well established that the loss of bone mass caused by estrogen deficiency in ovariectomized rats increases gradually, peaks and then stabilizes. The peaks identified in different studies do not always coincide; peaks from 30 to 90 days have been reported. ${ }^{26-29}$ The use of several time intervals in this study was appropriate to reveal the duration of estrogen deficiency that showed greater influence on the bone loss caused by induced periodontitis. Previous studies did not identify this relationship because of their use of a shorter period of time.

Studies of the possible molecular mechanisms involved, ${ }^{30}$ as well as longitudinal studies, are required to confirm the role of estrogen deficiency as an aggravator of periodontal disease.

\section{Conclusion}

The results of this study demonstrate that longterm estrogen deficiency affects ligature-induced alveolar bone loss.

\section{Acknowledgement}

The present study was partially funded by the Coordination for the Improvement of Higher Education (CAPES), Brazil.
6. Krall EA. Osteoporosis and the risk of tooth loss. Clin Calcium. 2006 Feb;16(2):287-90.

7. Grodstein F, Colditz GA, Stampfer MJ. Post-menopausal homone use and tooth loss: a prospective study. J Am Dent Assoc. 1996 Mar;127(3):370-7.

8. Paganini-Hill A. Estrogen replacement therapy in the elderly. Zentralbl Gynakol. 1996;118(5):255-61.

9. Duarte PM, Gonçalves PF, Sallum AW, Sallum EA, Casati MZ, Nociti FH Júnior. Effect of estrogen deficient state and its therapy on bone loss resulting from an experimental periodontits in rats. J Periodontol Res. 2004 Apr;39(2):107-10.

10. Anbinder AL, Prado M de A, Spalding M, Balducci I, Carvalho YR, Rocha RF. Estrogen deficiency and periodontal condition 
in rats: a radiographic and macroscopic study. Braz Dent J. 2006;17(3):201-7.

11. Cavaghi J, Soletti AC, Gaio EJ, Rösing CK. The effect of dexamethasone in the pathogenesis of ligature-induced periodontal disease in Wistar rats. Braz Oral Res. 2005 OctDec;19(4):290-4.

12. Souza DM, Ricardo LH, Kantorski KZ, Rocha RF. Influence of alcohol consumption on the alveolar bone level associated with ligature-induced periodontitis in rats. Braz Oral Res. 2009 Jul-Sep;23(3):326-32.

13. Souza DM, Rocha RF. Low caloric value of ethanol itself increases alveolar bone loss in ligature-induced periodontitis in male rats. Braz Oral Res. 2009 Oct-Dec;23(4):460-6.

14. Soletti AC, Gaio EJ, Rosing CK. Effect of neonatal clomipramine in the pathogenesis of ligature-induced periodontitis in Lewis rats. Acta Odontol Scand. 2009;67(2):94-8.

15. Sultan N, Rao J. Association between periodontal disease and bone mineral density in postmenopausal women: a cross sectional study. Med Oral Patol Oral Cir Bucal. 2011 May;16(3):e440-7.

16. Page RC, Offenbacher S, Schroeder HE, Seymour GJ, Kornman KS. Advances in the pathogenesis of periodontitis: summary of developments, clinical implications and future directions. Periodontol 2000. 1997 Jun;14:216-48.

17. Kharode YP, Sharp MC, Bodine PV. Utility of the ovariectomized rat as a model for human osteoporosis in drug discovery. Methods Mol Biol. 2008;455:111-24.

18. Bain JL, Lester SR, Henry WD, Bishop CM, Turnage AA, Naftel JP, et al. Comparative gender differences in local and systemic concentrations of pro-inflammatory cytokines in rats with experimental periodontitis. J Periodontal Res. 2009 Feb;44(1):133-40.

19. Bjornsson MJ, Velschow S, Stoltze K, Havemose-Poulsen A, Schou S, Holmstrup P. The influence of diet consistence, drinking water and bedding on periodontal disease in SpragueDawley rats. J Periodontal Res. 2003 Dec;38(6):543-50.
20. Klausen B, Evans RT, Sfintescu C. Two complementary methods of assessing periodontal bone level. Scand J Dent Res. 1989 Dec;97(2):494-9.

21. Fernandes MI, Gaio EJ, Oppermann RV, Rados PV, Rösing CK. Comparison of histometric and morphometric analyses of bone height in ligature-induced periodontitis in rats. Braz Oral Res. 2007 Jul-Sep;21(3):216-21.

22. Souza DM, Prado F de A, Prado M de A, Rocha RF, Carvalho, YR. Evaluation of two morphmetric methods of bone loss percentages caused by periodontitis in rats in different location. J Appl Oral Sci. 2010 Sep-Oct;18(5):493-7.

23. Beck JD. Periodontal implications: older adults. Ann Periodontol. 1996 Nov;1(1):322-57.

24. Becker AR, Handick KE, Roberts WE, Garetto LP. Osteoporosis risk factors in female dental patients. A preliminary report. J Indiana Dent Assoc. 1997 Summer 76(2):15-9.

25. Morya Y, Ito K, Muray S. Effects of experimental osteoporosis on alveolar bone loss in rats. J Oral Sci. 1998 Dec;40(4):171-5.

26. Johnson RB, Gilbert JA, Cooper RC, Dai X, Newton BI, Tracy $\mathrm{RR}$, et al. Alveolar bone loss one year following ovariectomy in sheep. J Periodontol. 1997 Sep;68(9):864-71.

27. Tanaka M, Ejiri S, Toyooka E, Kohno S, Ozawa H. Effects of ovariectomy on trabecular structures of rat alveolar bone. J Periodontal Res. 2002 Apr;37(2):161-5.

28. Tanaka M, Toyooka E, Kohno S, Ozawa H, Ejiri S. Long-term changes in trabecular structure of aged rat alveolar bone after ovariectomy. Oral Surg Oral Med Oral Pathon Oral Radiol Endod. 2003 Apr;95(4):495-502.

29. Wronski TJ, Cintrón M, Dann LM. Temporal relationship between bone loss and increased bone turnover in ovariectomized rats. Calcif Tissue Int. 1988 Sep;43(3):179-83.

30. Assuma R, Oates T, Cochran D, Amar S, Graves DT. IL-1 and TNF antagonistis inhibit the inflammatory response and bone loss in experimental periodontitis. J Immunol. 1998 Jan;160(1):403-9. 